Современные аспекты адаптации содержания обучения литературному чтению слепых младших школьников

Замашнюк Е.В. ${ }^{\text {, }}$ Круглова Т.А. ${ }^{b}$

ФГБОУ ВО «Российский государственный педагогический университет им. А.И. Герцена», Санкт-Петербург, Российская Федерация.

a ID ORCID: https://orcid.org/0000-0001-8513-2720, e-mail: zamashnyuk_ev@mail.ru

b id ORCID: https://orcid.org/0000-0001-6555-3499

Резюме: Статья посвящена проблеме обучения слепых младших школьников на уроках литературного чтения в начальных классах. Актуальность темы обусловлена необходимостью приведения в соответствие содержания обучения детей с глубокими нарушениями зрения с требованиями ФГОС НОО слепых обучающихся (вариант 3.2). В настоящее время педагоги школ слепых продолжают испытывать трудности по адаптации содержания обучения по данному учебному предмету. Целью исследования является анализ и обобщение имеющегося в тифлопедагогике опыта обучения данного контингента и определение направлений адаптации содержания обучения литературному чтению слепых младших школьников. Методы, применяемые в ходе исследования: анализ, описательный, сравнение. Анализ тифлопедагогического наследия свидетельствует о том, что обучение слепых младших школьников чтению имеет ряд особенностей, обусловленных негативным влиянием нарушения зрения на речевое, познавательное развитие, мотивацию к деятельности и может быть преодолено посредством адаптации содержания обучения. В свою очередь, направлениями адаптации могут являться адаптация содержания учебников, обогащение чувственного опыта, развитие речи и мышления, использование диффреренцированного подхода в обучении путем перераспределения учебного материала и разработки критериев оценки, соответствующих особенностям слепых. Результаты исследования имеют важное значение для практических работников школ слепых, так как позволяют реализовать дифференцированный подход в обучении и адаптировать содержание учебного предмета «Литературное чтение» в соответствии с особыми образовательными потребностями детей.

Ключевые слова: слепые, особые образовательные потребности, чувственный опыт, литературное чтение, слепые с остаточным зрением, адаптация содержания обучения, развитие речи и мышления, мотивация к читательской деятельности, средства обучения чтению.

Для цитирования: Замашнюк Е.В. Современные аспекты адаптации содержания обучения литературному чтению слепых младших школьников / Е.В. Замашнюк, Т.А. Круглова // Развитие образования. - 2020. - № 1 (7). C. 41-46. DOI:10.31483/r-74537.

\title{
Modern Aspects of Contents Adaptation in Teaching Literary Reading to Blind Elementary School Students
}

\author{
Elena V. Zamashnyuk ${ }^{a}$, Tamara A. Kruglovab \\ FSBEI of HE "Herzen State Pedagogical University of Russia", \\ Saint Petersburg, Russian Federation. \\ DORCID: https://orcid.org/0000-0001-8513-2720, e-mail: zamashnyuk_ev@mail.ru \\ b iD ORCID: https://orcid.org/0000-0001-6555-3499
}

\begin{abstract}
The article is focused on the problem of teaching blind elementary schoolers in literary reading lessons in elementary school. The relevance of the topic is due to the need to bring into compliance the content of the education of children with severe visual impairments with the requirements of the Federal State Educational Standards for blind students (option 3.2). At the present time, teachers of schools for blind children continue to experience difficulties in adapting the content of education in this subject. The aim of the article is to analyze and summarize the existing typhlopedagogical experience of teaching this group of children and to determine the directions for adapting the content of teaching literary reading to blind elementary students. Methods used in this study include analysis, description, and comparison. An analysis of the typhlopedagogical heritage suggests that teaching reading to blind elementary schoolers has a number of peculiarities due to the negative impact of visual impairment on their speech and cognitive development, motivation for activity; this can be overcome by adapting the content of education. In their turn, the directions of adaptation can be reached by adjusting the contents of textbooks, enriching the children's sensory experience, developing their speech and thinking, and using a differentiated approach in teaching by redistributing educational material and developing assessment criteria that are appropriate for the blind students' needs. The results of this study have important meaning for employees of schools for visually impaired children because they allow to implement a differentiated approach in teaching and to adapt the contents of the Literary reading school subject according to the special educational requirements of children.
\end{abstract}

Keywords: sensory experience, special educational needs, literary reading, blindness, residual vision, adaptation of learning content, development of speech and thinking, motivation to read, tools for teaching reading.

For citation: Elena V. Zamashnyuk, \& Tamara A. Kruglova (2020). Modern Aspects of Contents Adaptation in Teaching Literary Reading to Blind Elementary School Students. Razvitie obrazovaniya = Development of education, 1(7), 41-46. (In Russ.) DOI:10.31483/r-74537. 


\section{Кӗс̧ӗн класра вӗренекен суккӑр ачасен литратура вулавӗн содержанине адаптацилессин хальхи аспекчӗсем}

Замашнюк Е.В. ${ }^{\text {, }}$ Круглова Т.А. ${ }^{\text {b }}$

АВ ФПБ «А.И. Герцен ячӗллӗ Рас̧с̧ей патшалӑх педагогика университече̌» ВУ, Санкт-Петербург, Рас̧с̧ей Патшалӑхе̌.

a iD ORCID: https://orcid.org/0000-0001-8513-2720, e-mail: zamashnyuk_ev@mail.ru

b(iD ORCID: https://orcid.org/0000-0001-6555-3499

Аннотаци: Статьяна кӗс̧ӗн класра пӗлӳ илекен суккӑр ачасене литература вулавӗн урокӗсенче вӗрентессине халалланӑ. Темӑн паян кунхи пӗлтерӗшле̌хӗ кус̧ра пысӑк кӑлтӑк пур ачасем вуламалли вӗренў тексчӗсене ППВӗн ФГОСӗ ыйтнӑ пек (3.2 вариант) улӑштарса хатӗрлессипе с̧ыхӑннӑ. Хальхи вӑхӑтра суккӑрсен шкулӗнче ӗсллекен педагогсен вӗренӳ содержанине адаптацилес енчен йывӑрлӑх пур. Тӗпчев тӗллевӗ - ачасен эпир калакан контингентне вӗрентнин тифлопедагогикӑра пухӑннӑ опытне тишкерсе пӗтӗмлетесси тата литература тексчӗсене адаптацилемелли суул-йӗре тупасси. Тӗпчев вӑхӑтӗнче усӑ курнӑ меслетсем: тишкерӳ, сӑнлав, танлаштару. Тифлопедагогика эткерне тӗпчени суккӑр ачасене вулама вӗрентнин чылай уйрӑмлӑх пуррине кӑтартать. Вӗсем - начар курни каласуу тата ӑнланса илӳ аталанӑвне, ӗс̧ тума кирлӗ хавхаланӑва сиенлӗ витӗм кӳнипе сыхӑннӑ. Сиенлӗ витӗме вӗренӯ содержанине ансатлатнипе (адаптациленипе) сирсе яма пулать. Хӑй черечӗпе, адаптацин пӗр енӗ вӗренӳ кӗнекисен содержанине анстлатни, туйӑм опытне пуянлатни, пуплевпе шухӑшлава аталантарни, вӗренӳре кашни ачан уйрӑмлӑхне шута илсе вӗренў материалне с̧ӗнӗлле пайлани тата суккӑр ачасен урӑмлӑхне шута илсе ӑслайланӑ хаклав критерийӗ пулма пултарать. Тӗпчев пӗтӗмлетӗвӗ суккӑрсен шкулӗн ӗс̧ченӗсемшӗн пысӑк пӗлтерӗшлӗ, мӗншӗн тесен вӗренӯре кашни ачан уйрӑмлӑхне те, «Литература вулавӗ» предметӑн содержанине те шута илмелле.

Ключевые слова: литература вулавӗ, суккӑрсем, кӑшт куракан суккӑрсем, вӗреннӱре палӑракан ятарлӑ кирлӗлӗх, вӗренў содержанине кирлӗ пек улӑштарни (адаптацилени), туйӑм опычӗ, пуплевпе шухӑшлав аталанӑвӗ, вулама хавхалантарни, вулама вӗрентмелли хатӗрсем.

Цитатӑлама: Замашнюк Е.В. Кӗс̧ӗн класра вӗренекен суккӑр ачасен литратура вулавӗн содержанине адаптацилессин хальхи аспекчӗсем / Е.В. Замашнюк, Т.А. Круглова // Вӗренў аталанӑвӗ. - 2020. - № 1 (7). - С. $41-46$. DOI:10.31483/r-74537.

\section{Введение}

$\mathrm{P}$ еализация Федерального государственного стандарта начального общего образования для слепых обучающихся (далее - Стандарт) предусматривает обучение и воспитание школьников по ряду учебных дисциплин, в том числе и по «Литературному чтению», которое занимает ведущее место в развитии познавательной деятельности и обогащении жизненного опыта школьников. Важное место в обучении должно уделяться дифференцированному подходу, обеспечивающему учет особых образовательных потребностей слепых. Для этого, как отмечает Г.В. Никулина, необходимо пересмотреть все содержание образования в начальной школе, сделав основной упор на необходимость его адаптации [6]. В соответствии с этим нами была организована научно-практическая работа.

Целью работы являлось проведение анализа и обобщение имеющегося в тифлопедагогике опыта обучения детей данного контингента, а также определение направлений адаптации содержания обучения литературному чтению слепых младших школьников в начальной школе.

В психолого-педагогической литературе накоплен большой опыт обучения и воспитания слепых школьников. В связи с этим нами было высказана гипотеза, что адаптировать содержание по учебному предмету «Литературное чтение» возможно с учетом данных научных исследований об особенностях познавательного и речевого развития незрячих и коррекционной направленности процесса обучения. В свою очередь, направлениями адаптации могут являться: адаптация содержания учебников, обогащение чувственного опыта, развитие речи и мышления, повышение мотивации к читательской деятельности, использование дифференцированного подхода в обучении путем перераспределения учебного материала и разработки соответствующих особенностям незрячих критериев оценки. Ниже рассмотрим каждый из них.

В апробации содержания адаптации обучения слепых младших школьников литературному чтению приняли участие учителя начальных классов школ России: ГБОУ школы-интерната №1 им. К.К. Грота г. Санкт-Петербурга; ГКОУ Свердловской области «Верхнепышминской школы-интерната С.А. Мартиросяна, реализующей основные общеобразовательные программы»; ГБОУ Республики Карелии «Специальной (коррекционной) общеобразовательной школы-интерната №23»; ГКОУ «Школы-интерната Костромской области для слепых, слабовидящих детей»; МБОУ «Основной образовательной школы №58» г. Мурманска; МКОУ «Яшкур-Бодьинской школы-интерната». Научно-практическая работа проводилась в течение 4-х лет.

Результат. Анализ программно-методической литературы показал, что основной целью обучения слепых младших школьников на уроках «Литературного чтения» в начальных классах является обеспечение умений работать с различными видами текстов, развитие речевой деятельности, уточнение представлений об окружающем мире, формирование мировоззрения.

В начальной школе перед слепыми обучающимися стоит ряд как общих, так и специальных задач. Общие задачи полностью совпадают с общеобразовательными школами и решаются на одном и том же программном материале. Тем не менее содержание обучения для школ слепых отличается от общеобразовательных школ наличием коррекционной направленности ра- 
бочих программ и находит отражение в специальных задачах, перераспределении программного материала при обучении по варианту 3.2, включении специфичных видов деятельности на уроке, направленных на конкретизацию предметных представлений, лексическую и семантическую работу. Так, например, к специальным задачам можно отнести развитие осязательного и слухового восприятия (у слепых); развитие зрительного восприятия (у слепых с остаточным зрения); осуществление подготовительной работы к восприятию текста; совершенствование психических функций в процессе усвоения языка как средства общения: восприятия, анализа, синтеза, сопоставления, сравнения и др.

Уроки литературного чтения в школе слепых проводятся с использованием учебников общеобразовательной школы УМК «Школа России», изданных рельефно-точечным шрифтом Л. Брайля с аналогичным содержанием: «Литературное чтение» авторы Л.Ф. Климанова, В.Г. Горецкий, М.В. Голованова, Л.А. Винограская, М.В. Бойкина (М.: РЕПРО) для 2, 3, 4 классов. Таким образом, необходимой является адаптация содержания учебников исходя из требований Стандарта. Учебники, по которым сейчас обучаются разные категории незрячих, не учитывают особенности их ощущений, восприятий, представлений. В классах для слепых обучаются как тотально слепые дети, так и слепые со светоощущением и с остаточным зрением. Это требует от учителя адаптации содержания учебника, путём дополнения его рельефными рисунками, схемами с цветовым оформлением, что позволит осуществлять дифференцированный подход. На это указывают в своей работе Е.В. Замашнюк, А.В. Морозова [1].

Результаты анализа психолого-педагогических исследований позволяют говорить, что на современном этапе образования в начальных классах школ слепых важнейшей проблемой, требующей решения, является проблема обогащения чувственного опыта на уроках «Литературного чтения».

А.В. Потемкина в своей работе указывает, что овладение учебной деятельностью затрудняет недостаток чувственного опыта. Это проявляется в низком уровне умения осязательно обследовать предметы, рассматривать рельефную наглядность, как следствие, нечеткие, искаженные представления о качестве предметов и явлений [8]. Основы этой работы начинаются в 1 классе в период обучения грамоте при рассматривании рельефных картинок в учебнике «Азбука» для первого класса.

Исследования Т.А. Кругловой доказывают, что богатый чувственный опыт позволяет формировать правильные предметные представления об окружающих предметах, явлениях и абстрактных понятиях, развивать правильную устную и письменную речь, отвечающую стилистическим и грамматическим нормам русского языка. Это способствует решению ряда коррекционных задач [4]. Наибольшей спецификой обладает содержание подготовительной работы перед чтением литературного произведения. Обогатить чувственный опыт возможно путём использования на уроках по литературному чтению различных видов нагляд- ности: изобразительной (репродукций, иллюстраций, рельефных рисунков, которые рекомендуется оформить в «Альбом рельефных изображений»); объемной (скульптуры, бюстов, барельефов писателей и поэтов и др.); натуральных наглядных пособий; звуковой (аудиозаписи) и экранной (кинофильмов, кинофрагментов с тифлокомментированием). Работу с рельефным рисунком как с тифлоинформационной моделью необходимо проводить, придерживаясь определенных этапов в работе, которые соответствуют классическим рекомендациям использования графической наглядности, но имеют специфические особенности в практической реализации каждого этапа. При рассматривании картин (для слепых с остаточным зрением) целесообразно использовать лупы. Использование картины как вида подготовительной работы к лучшему восприятию текста литературного произведения даёт возможность младшим школьникам с глубоким нарушением зрения точно соотнести образ и слово, что положительно скажется как в процессе первичного восприятия произведения, так и при его анализе.

На современном этапе обучения младших школьников литературному чтению учителя начальных классов сталкиваются с трудностями, которые возникают у слепых обучающихся при понимании ими слов и фраз, пересказе текстов, явлений и их свойств. Это становится причиной формальных, недостаточно осмысленных знаний и затрудняет речевое развитие.

Современные представления о своеобразии развития речи слепых опираются на исследования Б.И. Коваленко, Ю.И. Кулагина, М.И. Земцовой. В их работах высказаны суждения о том, что у слепых детей соотношения слова и образа в процессе познания окружающего складываются по-другому, чем у зрячих. Это обусловлено тем, что речевая деятельность у незрячих формируется при отсутствии зрительного восприятия окружающей действительности. М.И. Земцовой установлено, что при ограничении чувственного опыта страдают и логические операции. Так, сравнения и обобщения сужаются и нередко становятся ошибочными. В то же время, признавая особенности в развитии детей данной категории, а именно несоответствие чувственных и словесных информаций об окружающем, они отмечают, что причиной своеобразия речевого развития незрячих является не столько слепота, сколько отсутствие специальной организации познавательной деятельности ребенка [3]. Поэтому, по мнению Н.С. Костючек, И.П. Чигриновой, трудности, с которыми связано развитие речи слепых школьников, могут быть скорректированы и в значительной мере преодолены под воздействием обучения.

Л.И. Моргайлик указывала на то, что самым эффективным условием для развития речи и мышления детей являются живые впечатления и наблюдения. Одним из видов работ, которые помогают формировать и уточнять представления школьников со зрительной депривацией, правильно и ярко воспринимать живописный образ произведения, являются экскурсионные наблюдения. Как правило, живописный образ представляет собой целостную картину, которая состоит 
из ряда отдельных образов: тактильных, зрительных, звуковых, обонятельных и др. Наличием подобных образов, причём у слепых преимущественно тактильных, у слепых с остаточным зрением - зрительно-тактильных, и объясняется трудность восприятия живописных лирических стихотворений младшими школьниками с глубокими нарушениями зрения. Организацию экскурсий рекомендуется проводить перед чтением произведений о природе или исторического характера [5]. На экскурсии школьники могут воспринимать окружающий мир, используя все сохранные анализаторы, манипулировать предметами, за которыми наблюдают, так как увиденное, услышанное и пережитое на экскурсии облегчает и обогащает эмоциональное восприятие и понимание картин природы, образов, раскрываемых в произведении.

Специфика обучения слепых на уроках литературного чтения может также проявляться в нежелании детей читать большие объемы текстов, необходимостью перечитывать текст и находить в нём отдельные отрывки, быстрой тактильной и физической утомляемостью. Скорректировать эти трудности можно за счет подбора разных видов работ при работе с текстом, проведением на уроке физминуток и физкультпауз.

В связи с тем, что обучение в начальной школе по варианту 3.2 составляет 5 лет, а изучение учебного предмета начинается со 2 класса, необходимо провести перераспределение программного материала учебников для 2-4 классов для нормально видящих. В связи с этими нами был разработан и апробирован в практических учреждениях один из вариантов перераспределения, представленный в таблице 1.

Перераспределение является примерным и может быть скорректировано учителем с учётом особенностей типологического развития обучающихся своего класса и их особых образовательных потребностей. Такое перераспределение материала устраняет перегрузку у слепых детей, создает благоприятные условия для правильной дозировки тактильной нагрузки, кон- кретизации представлений, выработки навыков самостоятельной работы и позволяет формировать навык чтения рельефно-точечного шрифта.

Формирование навыков чтения начинается в первом классе, продолжается в начальной школе и, по мнению Т.Г. Егорова, проходит три этапа: аналитический, синтетический и этап беглого синтетического чтения. У слепых школьников в силу особенностей чтения рельефно-точечного шрифта, отсутствия (при слепоте) и искажения (у слепых с остаточным зрением) зрительных образов затруднён переход от этапа к этапу. Как следствие - навык чтения формируется медленнее, чем у нормально видящих сверстников.

Г.В. Никулина, В.К. Рогушин, Е.В. Замашнюк, Л.Н. Авдеева, Л.Г. Кацап, А.П. Корнюшина указывают, что на первом этапе (аналитическом) темп чтения у слепых первоклассников медленный и его скорость находится в прямой зависимости как от сложности читаемых слогов, так и от сложности образа букв, представленных конфигурациями рельефных точек различной сложности. На втором этапе (синтетическом) возникают значительные трудности в осмыслении прочитанного. Из-за особенностей познавательной деятельности для них характерно своеобразие развития активного и пассивного словаря, вследствие чего возникают трудности в развитии лексико-грамматического строя речи [7].

В ФГОС НОО представлены нормативы темпа (скорости) чтения к концу обучения в начальной школе: на базовом уровне ученик должен читать 100-120 слов в минуту. В АООП НОО для слепых обучающихся указаны нормативы примерного темпа чтения для выпускника начальной школы слепых (вариант 3.2): читать сознательно, правильно и выразительно незнакомый текст вслух (темп чтения 65-80 слов в минуту и «про себя» (темп чтения 75-100 слов в минуту). Каждая школа индивидуально разрабатывает критерии оценки навыка чтения, которые помимо темпа чтения учитывают иные показатели техники чтения (способ, осоз-

Таблица 1

Примерное перераспределение учебного материала по «Литературному чтению» для слепьх обучающихся (вариант 3.2)

Table 1

Approximate redistribution of educational material on "Literary reading" for blind elementary school students (option 3.2)

Основные раздель по учебнику 2 класса: «Самое великое чудо», «Устное народное творчество», «Люблю природу русскую», «Русские писатели», «О братьях наших меньших», «Из детских журналов», «Писатели - детям», «Люблю природу русскую. Весна»

\section{3 класс}

Основные раздель по учебнику 2 класса: «Я и мои друзья», «И в шутку, и всерьёз», «Литература зарубежных стран»

Основные разделы по учебнику 3 класса: «Самое великое чудо», «Устное народное творчество. Сказки», «Поэтическая тетрадь 1», «Великие русские писатели», «Поэтическая тетрадь 2», «Литературные сказки», «Былицы-небылицы»

\section{4 класс}

Основные раздель по учебнику 3 класса: «Поэтическая тетрадь 1», «Люби живое», «Поэтическая тетрадь 2», «Собирай по ягодке - наберешь кузовок», «По страницам детских журналов», «Зарубежная литература»

Основные раздель по учебнику 4 класса:

«Летописи. Былины. Жития», «Чудесный мир классики», «Поэтическая тетрадь»,«Литературные сказки», «Делу время -потехе час»

5 класс

Основные раздель по учебнику 4 класса: «Страна детства», «Поэтическая тетрадь», «Природа и мы», «Поэтическая тетрадь», «Родина», «Страна фантазия», «Зарубежная литература» 
Требования программы для слепых обучающихся к темпу и показателям техники чтения (вариант 3.2)

Table 2

Requirements of the program for blind elementary school students to the tempo and indicators of reading technique (option 3.2)

\begin{tabular}{|c|c|c|}
\hline Класс & $\begin{array}{l}\text { Примерный темп } \\
\text { (скорость) чтения } \\
\text { слов в минуту }\end{array}$ & Показатели техники чтения (способ, осознанность, правильность, выразительность) \\
\hline 1 & $30-40$ вслух & $\begin{array}{l}\text { Отчётливое произношение слов и выражений. Соблюдение правильных ударений } \\
\text { в словах }\end{array}$ \\
\hline 2 & $\begin{array}{l}40-50 \text { вслух, } \\
\text { «про себя» } 50-60\end{array}$ & $\begin{array}{l}\text { Чтение целыми словами, по слогам только сложные слова. Чтение осознанное, без } \\
\text { ошибок. Чтение текста отдельными предложениями. Понижение голоса на точках }\end{array}$ \\
\hline 3 & $\begin{array}{l}50-60 \text { вслух, } \\
\text { «про себя» } 60-70\end{array}$ & $\begin{array}{l}\text { Отчётливое произношение слов. Соблюдение ударений в словах. Соблюдение пауз, } \\
\text { отделяющих одно предложение от другого и интонации при чтении }\end{array}$ \\
\hline 4 & $\begin{array}{c}\text { 60-70 вслух, } \\
\text { «про себя» 70-80 }\end{array}$ & $\begin{array}{l}\text { Выделение при чтении важных по смыслу слов. Соблюдение пауз и интонаций, } \\
\text { соответствующих знакам препинания в конце простого предложения. } \\
\text { Соблюдение пауз между предложениями и частями текста }\end{array}$ \\
\hline 5 & $\begin{array}{l}70-80 \text { вслух, } \\
\text { «про себя» } 75-100\end{array}$ & Умение самостоятельно подготовиться к выразительному чтению \\
\hline
\end{tabular}

нанность, правильность, выразительность). В помощь учителю-тифлопедагогу нами разработаны и апробированы требования к примерному темпу и показателям техники чтения слепых младших школьников, представленные в таблице 2 .

В то же время, как указывают Е.В. Замашнюк, Т.А. Круглова, при разработке критериев оценивания для слепых необходимо учитывать динамику продвижения каждого обучающегося, исходя из особенностей развития осязания, мелкой моторики, познавательной деятельности и развития речи детей [2].

Заключение. Исходя из вышесказанного, при адаптации содержания обучения слепых младших школь- ников литературному чтению необходимо, с одной стороны, реализовать задачи цензового образования, с другой - обеспечить коррекционную направленность образовательного процесса данного контингента. Это позволит создать условия, направленные на удовлетворение особых образовательных потребностей слепых школьников на уроках по литературному чтению: расширять чувственный опыт, формировать познавательные интересы и перцептивные процессы, развивать все стороны речи путем обогащения языковых и неязыковых средств общения.

\section{Список литературы}

1. Замашнюк Е.В. Обогащение чувственного опыта слепых на уроках литературного чтения посредством адаптации учебно-методического аппарата учебника / Е.В. Замашнюк, М.В. Морозова // Материалы XXIII Международной конференции «Ребенок в современном мире. Дети и информационное пространство». - СПб., 2016. С. $372-375$.

2. Замашнюк Е.В. Современные подходы к адаптации контрольно-измерительных материалов для слепых и слабовидящих по учебным предметам в свете реализации ФГОС НОО обучающихся с ОВЗ // Современные тенденции развития системы образования: материалы Междунар. науч.-практ. конф. (Чебоксары, 27 март 2018 г.). - Чебоксары: ИД «Среда», 2018. - С. 290-293.

3. Земцова М.И. Пути компенсации слепоты в процессе познавательной и трудовой деятельности. - М.: Издво АПН РСФСР, 1956.

4. Круглова Т.А. Понимание лексического значения слов младшими школьниками с нарушением зрения // Экология детства: особый ребенок и общество [Текст]: материалы XXV Международной конференции «Ребенок в современном мире. Экология детства». - СПб., 2018. - С. 330-333.

5. Моргайлик Л.И. Методика обучения русскому языку младших слабовидящих школьников: учеб. пособие / Л.И. Моргайлик. - Л.: Изд-во ЛГПИ, 1986. - 85 с.

6. Никулина Г.В. Адаптация содержания образования в контексте реализации ФГОС для слепых и слабовидящих // Школа для всех: образование слепых и слабовидящих: сборник статей / под общ. ред. Г.В. Никулиной. СПб.: Граница, 2015. - 96 с.

7. Никулина Г.В. Рельефно-точечная система: обучение чтению и письму: учебно-методическое пособие / Г.В. Никулина, В.К. Рогушин, Е.В. Замашнюк [и др.]. - СПб.: Изд-во РГПУ им. А.И. Герцена, 2017. - 459 с.

8. Потемкина А.В. Особенности преподавания учебных предметов слепым и слабовидящим обучающимся в условиях реализации ФГОС НОО ОВЗ: методические рекомендации в 3-х частях. Ч. 3 / А.В. Потемкина, Г.В. Никулина; под ред. Г.В. Никулиной. - СПб.: Изд-во РГПУ им. А.И. Герцена, 2018. - 260 с.

\section{References}

1. Zamashniuk, E. V., \& Morozova, M. V. (2016). Obogashchenie chuvstvennogo opyta slepykh na urokakh literaturnogo chteniia posredstvom adaptatsii uchebno-metodicheskogo apparata uchebnika. Materialy XXIII Mezhdunarodnoi konferentsii "Rebenok v sovremennom mire. Deti i informatsionnoe prostranstvo", 372-375. SPb. 
2. Zamashniuk, E. V. (2018). Sovremennye podkhody k adaptatsii kontrol'no-izmeritel'nykh materialov dlia slepykh i slabovidiashchikh po uchebnym predmetam v svete realizatsii FGOS NOO obuchaiushchikhsia s OVZ. Sovremennye tendentsii razvitiia sistemy obrazovaniia, 290-293. Cheboksary: ID "Sreda".

3. Zemtsova, M. I. (1956). Puti kompensatsii slepoty v protsesse poznavatel'noi i trudovoi deiatel'nosti. M.: Izdatel'stvo APN RSFSR.

4. Kruglova, T. A. (2018). Ponimanie leksicheskogo znacheniia slov mladshimi shkol'nikami s narusheniem zreniia. Ekologiia detstva: osobyi rebenok i obshchestvo : materialy XXV Mezhdunarodnoi konferentsii "Rebenok v sovremennom mire. Ekologiia detstva", 330-333. SPb.

5. Morgailik, L. I. (1986). Metodika obucheniia russkomu iazyku mladshikh slabovidiashchikh shkol'nikov: ucheb. posobie., 85. L.: LGPI.

6. Nikulina, G. V. (2015). Adaptatsiia soderzhaniia obrazovaniia v kontekste realizatsii FGOS dlia slepykh i slabovidiashchikh. Shkola dlia vsekh: obrazovanie slepykh i slabovidiashchikh: sbornik statei, 96. SPb.: Granitsa.

7. Nikulina, G. V., Rogushin, V. K., \& Zamashniuk, E. V. (2017). Rel'efno-tochechnaia sistema: obuchenie chteniiu i pis'mu: uchebno-metodicheskoe posobie., 459. SPb.: Izd-vo RGPU im. A.I. Gertsena.

8. Potemkina, A. V., \& Nikulina, G. V. (2018). Osobennosti prepodavaniia uchebnykh predmetov slepym i slabovidiashchim obuchaiushchimsia v usloviiakh realizatsii FGOS NOO OVZ: metodicheskie rekomendatsii v 3-kh chastiakh., 3, 260. SPb.: Izdatel'stvo RGPU im. A.I. Gertsena.sadov i shkol rannego razvitiia., 93. Rostov n/D: Feniks.

\author{
Информация об авторах \\ Замашнюк Елена Вадимовна - \\ канд. пед. наук, доцент кафедры \\ тифлопедагогики, ФГБОУ ВО \\ «Российский государственный \\ педагогический университет им. \\ А.И. Герцена», Санкт-Петербург, \\ Российская Федерация. \\ Круглова Тамара Александровна - \\ канд. пед. наук, доцент кафедры \\ тифлопедагогики, ФГБОУ ВО \\ «Российский государственный \\ педагогический университет им. \\ А.И. Герцена», Санкт-Петербург, \\ Российская Федерация. \\ Information about the authors \\ Elena V. Zamashnyuk - candidate \\ of pedagogical sciences, associate \\ professor, Department for Methods \\ of Teaching the Blind, FSBEI of \\ HE "Herzen State Pedagogical \\ University of Russia", Saint \\ Petersburg, Russian Federation. \\ Tamara A. Kruglova - candidate \\ of pedagogical sciences, associate \\ professor, Department for Methods \\ of Teaching the Blind, FSBEI of \\ HE "Herzen State Pedagogical \\ University of Russia", Saint \\ Petersburg, Russian Federation.
}

Авторсем суинчен пӗлтерни Замашнюк Елена Вадимовна педагогика ӑслӑлӑхӗн к-чӗ, $\mathrm{AB}$ ФПБ «А.И. Герцен ячӗлле̌ Рас̧сей патшалӑх педагогика университече̌» ВУн тифлопедагогика кафедрин доценчё, Санкт-Петербург, Рас̧с̧ей Патшалӑхе̌. Круглова Тамара Александровна педагогика ӑслӑлӑхӗн к-чӗ, $\mathrm{AB}$ ФПБ «А.И. Герцен ячӗллӗ Рас̧сей патшалӑх педагогика университечё» ВУн тифлопедагогика кафедрин доценчӗ, Санкт-Петербург, Рас̧с̧ей Патшалӑхе̌. 